\title{
Balance comparativo de la normatividad sobre fronteras en cuatro países colindantes del Caribe
}

\section{Comparative balance of border regulations in four neighboring Caribbean countries}

Recibido el 23 de abril de 2015. Aceptado el 16 de diciembre de 2015.

* Autor para correspondencia: Silvia Cristina Mantilla Valbuena, correo electrónico: scmantillav@ unal.edu.co

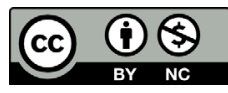

Todos los contenidos de Estudios Fronterizos se publican bajo la licencia Creative Commons Atribución no comercial 2.5 México, y pueden ser usados gratuitamente para fines no comerciales, dando el crédito a los autores y a la revista Estudios Fronterizos.

\begin{abstract}
${ }^{1}$ Universidad Nacional de Colombia. Grupo de Investigación en Relaciones Internacionales y Asuntos Globales, Bogotá, Colombia, correos electrónicos: scmantillav@unal.edu.co, cchaconh@ unal.edu.co
\end{abstract}

\section{Resumen}

El artículo busca indagar si existen potencialidades para la integración fronteriza entre cuatro países colindantes del Caribe: Colombia, Nicaragua, Panamá y Costa Rica. Se enmarca la discusión en el concepto de lo "transfronterizo" y de la integración entre entidades subnacionales de dos o más Estados nación, haciendo especial énfasis en el papel jugado por las sociedades que habitan los territorios fronterizos. Se utiliza un modelo comparativo de análisis de la reglamentación sobre fronteras en los distintos niveles territoriales de cada país, a partir de los elementos jurídicos relevantes, los procesos autonómicos y la descentralización, para concluir que entre más modernas han sido las normativas fronterizas y las reformas constitucionales, políticas y administrativas en cada uno de los países, mayores son sus posibilidades para la integración transfronteriza. Colombia y Nicaragua cuentan con la potencialidad más alta, mientras Panamá y Costa Rica evidenciaron una precaria potencialidad para la integración de sus fronteras.

Palabras clave: normatividad fronteriza, ordenamientos jurídico administrativos, integración transfronteriza, cooperación, región Caribe.

\begin{abstract}
This article seeks to investigate whether there is a potential for border integration among four adjoining Caribbean countries: Colombia, Nicaragua, Panama and Costa Rica. The discussion is part of the "cross-border" concept and the integration of subnational entities in two or more nation states, with particular emphasis on the role played by the societies that inhabit border regions. A comparative analysis model is used to assess border regulations in each country's
\end{abstract}

CÓMO CITAR: Mantilla, S. C. y Chacón C. (2016). Balance comparativo de la normatividad sobre fronteras en cuatro países colindantes del Caribe [Comparative balance of border regulations in four neighboring Caribbean countries]. Estudios Fronterizos, 17(34), 1-20, https://doi.org/10.21670/ref.2016.34.a01 
various territorial levels based on relevant legal elements, autonomous processes and decentralization. The article concludes that the more modern each country's border regulations and constitutional, political and administrative reforms are, the greater the likelihood of cross-border integration. Colombia and Nicaragua have the highest potential for integrating their borders, whereas Panama and Costa Rica have the lowest potential.

Keywords: border regulations, administrative legal system, border integration, cooperation, Caribbean region.

\section{Introducción ${ }^{2}$}

Pese a la existencia de diversas iniciativas de integración regional y cooperación entre los llamados países en el Gran Caribe, ${ }^{3}$ es posible afirmar que en buena parte de sus fronteras marítimas, no se han consolidado aún estrategias de integración transfronteriza que trasciendan el rígido marco del Estado nación y la concepción puramente territorial de dichas fronteras. La dificultad en la concreción de políticas de integración que articulen dinámicas transfronterizas de manera consistente y acorde a las necesidades de los actores que se desenvuelven en los contextos locales, tanto territoriales como marítimos, evidencia el escaso papel que se ha otorgado a una integración "desde abajo" frente al conjunto de iniciativas que continúan desarrollándose desde los centros de poder de los Estados nación. ${ }^{4}$

Existe toda una unidad socio cultural y ambiental conformada por los territorios y áreas marítimas que circundan buena parte del Caribe occidental entre países como Colombia, Nicaragua, Costa Rica y Panamá. ${ }^{5}$ Esta unidad está representada en la configuración de sus territorios y poblaciones costeras: los municipios de Bluefields, Puerto Cabezas y Corn Island en Nicaragua, Limón y Cahuita en Costa Rica, Bocas del Toro y Colón en Panamá, y el Departamento Archipiélago de San Andrés, Providencia y Santa Catalina en Colombia. Dichos territorios experimentaron dinámicas de poblamiento similares a partir de la colonización inglesa del Caribe occidental (Sandner, 2003) que inició en el

\footnotetext{
${ }^{2}$ El artículo está vinculado al proyecto de investigación titulado "La integración fronteriza y la vecindad entre Colombia y los países del Gran Caribe: estrategias para la construcción de una Región de Integración Transfronteriza". El proyecto es liderado por la Universidad Nacional de Colombia Sede Caribe.

${ }^{3}$ Desde un punto de vista geográfico y cultural al Gran Caribe se le conoce como el conjunto de Estados insulares y territoriales pertenecientes a la Asociación de Estados del Caribe (AEC). La AEC está compuesta por los miembros de la Comunidad del Caribe (CARICOM), los cinco países centroamericanos (Nicaragua, Guatemala, Costa Rica, Honduras, el Salvador) y por México, Colombia, Venezuela, Panamá y Cuba. El CARIcom a su vez, se compone de sus miembros plenos: Antigua y Barbuda, Bahamas, Barbados, Belice, Dominica, Granada, Guyana, Haití, Jamaica, Montserrat, Santa Lucía, San Cristóbal y Nieves, San Vicente y las Granadinas, Surinam, Trinidad y Tobago; sus miembros asociados: Anguila, Bermuda, Islas Caimán, Islas Turcas y Caicos e Islas Vírgenes Británicas; y sus miembros observadores: Aruba, Antillas Neerlandesas, Colombia, México, Puerto Rico, República Dominicana y Venezuela.

${ }^{4}$ Un estudio representativo de esta problemática en la región centroamericana se encuentra en Centro Studi di Politica Internazionale (CESPI, 2011).

${ }^{5}$ Del conjunto de países que conforman el Gran Caribe se escogieron para esta investigación cuatro países representativos (Colombia, Nicaragua, Panamá y Costa Rica) debido a que conforman parte del escenario de integración propio del área que ha sido denominada geográficamente como el Caribe Occidental (Sandner, 2003) y por ser todos países con los que Colombia actualmente comparte fronteras dada la ubicación geoespacial del archipiélago de San Andrés, Providencia y Santa Catalina. En estos territorios, se han desarrollado históricamente fuertes redes de intercambios poblacionales, económicos y socio culturales que podrían consolidarse en procesos transfronterizos de integración regional.
} 
siglo XVI y que junto con la conformación de las sociedades esclavistas e indígenas que tuvieron lugar en la zona, produjeron una lengua "creole" común, formas de subsistencia, usos y costumbres gastronómicas y culturales compartidas que perviven y numerosas comunidades y familias binacionales que se fueron ubicando a lado y lado de las fronteras a partir de las dinámicas de intercambio, diásporas y movilidad informal en la región.

$\mathrm{Al}$ iniciarse los procesos de consolidación de los estados centroamericanos en el siglo XIX, estos territorios y sus culturas pasaron a formar parte de las dinámicas nacionales de administración jurídico-territorial, por las cuales quedaron a su vez, fragmentadas y dependientes de modelos de organización estatal disímiles, que en tiempos recientes, suponen un desafío a las posibilidades reales que tienen las sociedades fronterizas de armonizar proyectos de integración y cooperación que respondan a las lógicas de intercambio propias de esta unidad geográfica (como se observa en la Figura 1) y sociocultural.

Figura 1: Delimitación de la zona fronteriza a partir de las poblaciones colindantes entre Colombia, Panamá, Costa Rica y Nicaragua en el Caribe

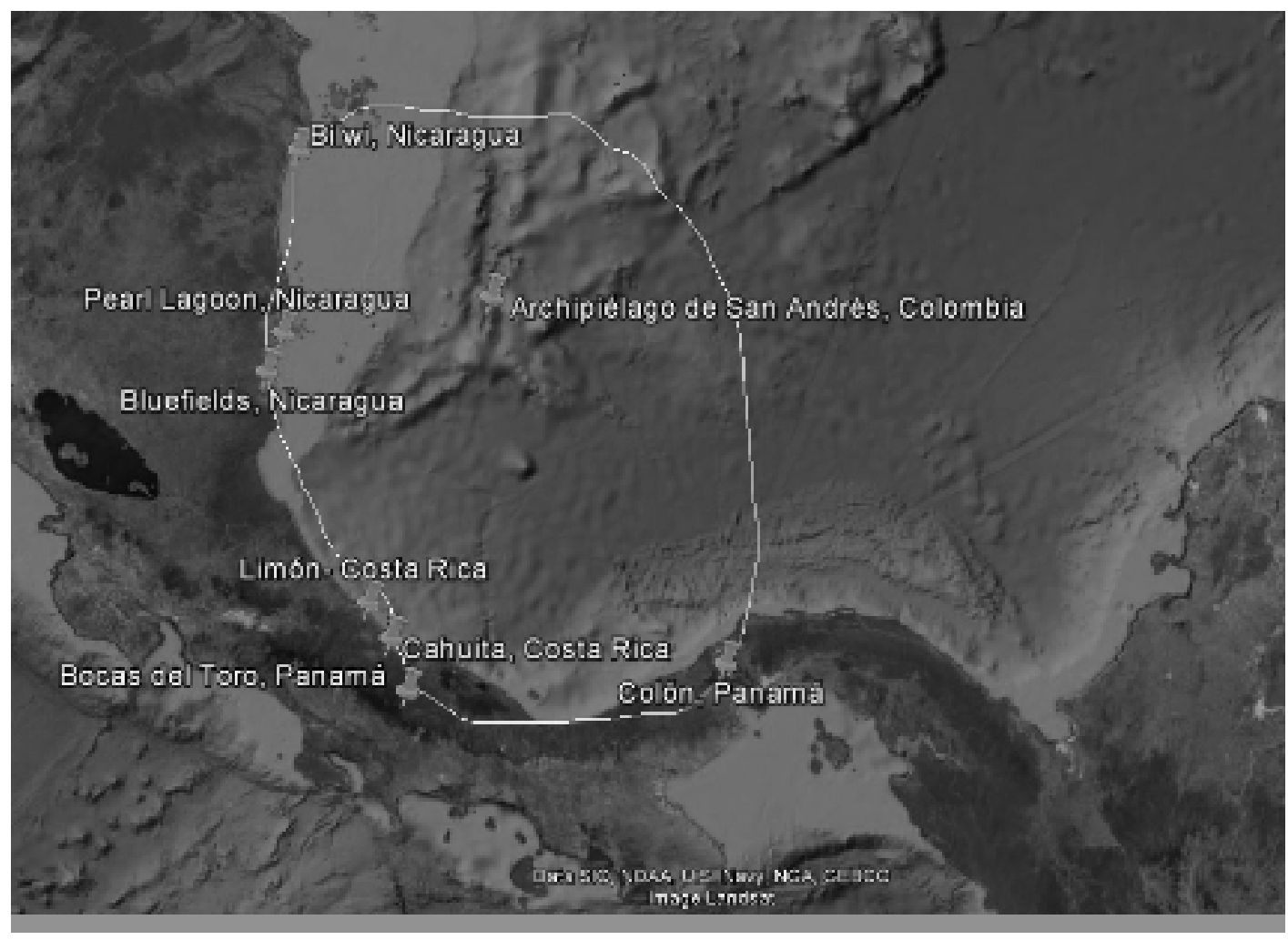

Fuente: Elaboración propia sobre mapa de Google Earth. 
Recientemente, el fallo de la Corte Internacional de La Haya frente al diferendo marítimo y territorial entre Colombia y Nicaragua ${ }^{6}$ evidenció la ausencia de instrumentos cooperativos que le permitieran a las instituciones y sociedades fronterizas apropiarse de su entorno para asegurar el manejo conjunto de los recursos de los cuales dependen para su sobrevivencia cientos de familias, pescadores artesanales y diversos grupos sociales que viven de su estrecha e indivisible relación con el mar. El desconocimiento y la falta de armonización de los instrumentos normativos e institucionales que en cada país y localidad podrían perfilar a los entes locales fronterizos como niveles con suficiente autonomía para desplegar estrategias de integración y cooperación más allá de sus fronteras de cara al mar Caribe, han acentuado igualmente la situación de fragmentación regional.

En aras de superar los rígidos marcos de relacionamiento estatal y ofrecer a los actores locales herramientas para la integración regional, es preciso revisar entonces las bases normativas y político-administrativas de cada país para identificar tanto los obstáculos como las potencialidades, que desde su configuración jurídica y territorial podrían tener las localidades fronterizas respecto a la formulación y ejecución de políticas de integración que favorezcan las necesidades y dinámicas de las sociedades fronterizas de la región Caribe.

En este artículo nos proponemos demostrar que los territorios de frontera caribeños que pertenecen a los cuatro países escogidos para el análisis comparativo (Colombia, Nicaragua, Panamá y Costa Rica) presentan niveles disímiles de potencialidad para la integración transfronteriza. Su capacidad jurídica y territorial para establecer políticas de integración transfronterizas dependen de un mayor o menor desarrollo de las normas y ordenamientos jurídico-administrativos en los ámbitos nacional, local y fronterizo, que posibilitarían la movilización de recursos y su agenciamiento por parte de los actores sociales y políticos interesados en el logro de la integración.

Para el desarrollo de la investigación se empleó una metodología de carácter cualitativa y comparada en la que se revisaron los elementos jurídicos y los ordenamientos territoriales en distintos niveles (nacional, local y fronterizo) de cada uno de los países estudiados, haciendo especial énfasis en la legislación sobre aspectos fronterizos, normativas de autonomía territorial y reglamentaciones especiales propicias al logro de la integración transfronteriza. A partir de dicha revisión se realizaron las matrices de análisis que arrojaron diversos resultados y que serán presentadas con detalle en los apartes comparativos.

En la primera parte, se ofrece una breve perspectiva teórica acerca de la integración fronteriza como marco de referencia para abordar el caso aquí propuesto. Seguidamente, el artículo se enfoca en el ejercicio comparado, a partir de la exploración normativa realizada en cada uno de los países, arrojando resultados sobre potencialidades y limitaciones jurídicas y administrativas que permiten o impiden poner en práctica acciones de integración transfronterizas. Finalmente, se plantean algunas reflexiones y recomendaciones en relación a la consolidación de una política de integración entre los territorios de frontera en el Caribe.

\footnotetext{
${ }^{6}$ En el año 2001 Nicaragua presentó ante la Corte Internacional de Justicia (CIJ) con sede en La Haya, una demanda contra Colombia por la posesión del archipiélago de San Andrés, Providencia y Santa Catalina y por la definición de los límites marinos entre ambos países. Pese a que en 2007 la Corte falló a favor de Colombia en cuanto a la posesión sobre las formaciones territoriales del Archipiélago, finalmente en el año 2012 definió una nueva delimitación marítima favorable a Nicaragua, que ocasionó una crisis diplomática entre los dos países así como un vacío de legitimidad del Estado colombiano en el archipiélago.
} 


\section{Conceptualizando lo "transfronterizo"}

Las "regiones transfronterizas" podrían ser definidas como unidades territoriales compuestas de unidades subnacionales de dos o más Estados nación y que se edifican a partir de formas específicas de innovación del espacio de forma física (infraestructura), o se construyen a partir de marcos institucionales o de vínculos de las comunidades a ambos lados de la frontera; los intereses comunes y las oportunidades atractivas hacen que dichas comunidades cooperen a pesar de sus posibles diferencias (Buursink, 2001, p. 17; Jessop, 2003, p. 188; Söderbaum, 2005, p. 92) ${ }^{8}$ Como se puede ver en la definición, las formas de edificación de una región transfronteriza no responden necesariamente a un solo proceso dentro de dicho espacio geográfico, sino que se pueden identificar cinco tipos de edificación de este tipo de microrregiones, a saber: físico-geográficas, culturales, económicas, políticas y zonas de planeación y administración (Söderbaum, 2005, p. 93).

Por su parte, en un debate teórico entre un modelo geoeconómico ${ }^{9}$ y un modelo de proyecto territorial ${ }^{10}$ de las regiones transfronterizas, Sohn (2014, p. 593) defiende la hipótesis según la cual, tanto las regiones como la integración transfronteriza no se generan sólo por el desbordamiento del límite estatal ni por el simple compartimiento de una historia común de un lado y otro de la frontera, sino que este fenómeno aparece como contingente y atado a la capacidad de agencia de los actores regionales y locales que aprovechan o no el contexto transfronterizo donde se encuentran inmersos. Así, el autor empata con las afirmaciones de Buursink (2001, p. 17) quien afirma que la cooperación y la integración requieren del deseo de las partes por resolver problemas comunes, que no se da necesariamente por la naturaleza de adyacencia entre dos territorios locales, sino por la voluntad de acción entre las partes involucradas.

\footnotetext{
${ }^{7}$ Vale la pena destacar el ejercicio que realiza Buursink (2001, pp. 15-17) en torno a la definición de los relacionamientos entre niveles locales. En primera instancia, pone en debate el concepto inicial de "ciudades gemelas" e inicia una explicación de la evolución conceptual pasando por ciudades dobles (es decir, una ciudad que creció a semejanza de su ciudad contigua); ciudades hermanas (ciudades con voluntad de relacionamiento sin vínculos territoriales de forma contigua); ciudades vecinas (...) ciudades compañeras (no existen similitudes pero hay una distancia corta entre ellas); ciudades fronterizas internacionales (evocación de aglomeración más que de flujo). Tras este repaso, el autor concluye que la definición más compleja es la de ciudades transfronterizas porque implican el flujo, la posibilidad de cercanía o distancia, la capacidad de agencia de los actores en ambas ciudades y la vinculación o diferencia a través de aspectos culturales, además de compartir actividades mutuas.

8 En el caso particular de la frontera colombiana con sus vecinos del Caribe, tendría que explorarse tanto teórica como prácticamente la posibilidad de una región transfronteriza haciendo especial énfasis en su carácter marítimo. No obstante y aunque existen experiencias documentadas sobre regiones de integración transfronteriza en contexto marítimo, como el caso del Canal de la Mancha entre Inglaterra y Francia (Church y Reid, 1999) o el del Mar Negro (Stelmakh, s.f.), no hay una teorización profunda sobre las particularidades que implica la integración transfronteriza en dicho ámbito.

${ }^{9}$ Basado en una forma de generación de valor a partir de la movilización de la frontera como espacio económico, presentando una fuerte y funcional división del espacio para la producción y una cooperación meramente instrumental y de inversión con altas tasas de crecimiento que no resuelve las posibles disparidades entre las regiones que conforman la zona transfronteriza por no apuntar a una convergencia territorial (Sohn, 2014, pp. 593, 597-599).

${ }^{10} \mathrm{El}$ cual tiene énfasis en la convergencia de ambos lados de la frontera a través de un proceso de hibridación e innovación que requiere un reconocimiento del espacio fronterizo a partir del imaginario territorial-simbólico. En este modelo, se presentan como fundamentales aspectos que no son materiales ni tangibles como lo son la confianza entre los actores locales a cada lado de la frontera, el sentido de pertenencia, la percepción del otro y la consolidación de actividades simbólicas que fortalezcan el flujo y la identificación cultural-social que erosionen la barrera nacional-fronteriza (Sohn, 2014, pp. 599-600), Grimson (2003, pp.13-24), Lugo (2003, pp. 63-86), Sahlins (2000).
} 
Podríamos afirmar entonces que la integración transfronteriza y la construcción de regiones es un proceso que aunque requiere de unos factores materiales (cercanía y potencialidades espaciales) implica también unos elementos no tangibles (identidades y pertenencias comunes) que se cristalizan en la toma de decisión de las partes de cooperar para impulsar proyectos conjuntos que puedan ser de provecho, y que permitan la movilización de los recursos ya mencionados en pro de un fin común. Es decir, la decisión reposa en los entes locales involucrados y por ello, revisar las potestades que tienen para la toma de estas decisiones es fundamental en la formulación de un proyecto de integración transfronteriza entre los países del Caribe.

La revisión de los ordenamientos jurídicos nacionales, para dar cuenta de las posibilidades que se abren desde los espacios locales, permite la identificación de las herramientas que tienen estos actores para actuar en sus espacios fronterizos. Es de vital importancia dar un sustento jurídico a las posibles actividades transfronterizas que permitan sacar de la informalidad los vínculos y relacionamientos de estos actores en una zona susceptible de encontrarse en disputa, generando recelo por parte de las autoridades nacionales. Una revisión de la normatividad en distintos niveles del orden nacional permitirá ver los límites y las posibilidades que tienen los actores de incidir y decidir con vistas a la conformación de una región de integración transfronteriza en el Gran Caribe.

\section{Exploración jurídico-normativa: Herramientas para los actores frente a la formación de una Región de Integración Transfronteriza en el Caribe}

Para el análisis comparativo que aquí se propone, se requiere revisar los elementos que los ordenamientos jurídicos en cada uno de los países brindan a los actores locales que, como hemos venido sosteniendo, son los agentes primordiales del proceso integrador en las fronteras. A pesar de que las dinámicas efectivas de la descentralización puedan o no ser profundas, permitiendo niveles de autonomía a los niveles locales, la normatividad puede ser un punto de encuentro para el desenvolvimiento de acciones que logren consolidar procesos de integración transfronterizos.

Dicho esto, la revisión se enfocó en los elementos jurídicos que tuvieran relevancia para la configuración de una región de integración transfronteriza. Con ello, del nivel nacional se recurrirá a la Constitución Política de cada país y a las leyes que refieran a su política exterior, en donde se puede delinear tanto la visión de integración y de frontera que tiene cada país, como el papel que tiene el nivel nacional en la proyección internacional de sus entes locales vía su gabinete de exteriores.

Del ámbito fronterizo, se indagarán las normativas que reglamenten las fronteras del país, en la búsqueda de regímenes especiales para la frontera, posibilidades de entablar diálogos con entes territoriales similares y otras excepcionalidades que se les pueda brindar a estas zonas limítrofes.

Por último, se revisará la normativa del nivel local, en donde se desglosarán las potestades de los municipios, buscando elementos de autonomía como la firma de acuerdos, la propuesta de proyectos de ley y legislaciones especiales dentro de los territorios estudiados.

Con esto, el interés es mirar qué países brindan mayores potencialidades a sus entes locales fronterizos para proyectarse internacionalmente, para que sus actores puedan reconocer las posibilidades que el ordenamiento jurídico les da y edifiquen una 
estrategia para el logro de una integración transfronteriza. De esta forma, la medición de potencialidades se hará a partir de los indicadores expuestos en las tablas 1, 2 y 3.

Tabla 1: Variables e indicadores para el ámbito nacional

\begin{tabular}{|c|c|c|}
\hline $\begin{array}{c}\text { Tipo de } \\
\text { normatividad }\end{array}$ & \multicolumn{1}{|c|}{$\begin{array}{c}\text { Elementos para medición de la } \\
\text { potencialidad }\end{array}$} & \multicolumn{1}{c|}{$\begin{array}{c}\text { Ponderación de la } \\
\text { potencialidad }\end{array}$} \\
\hline \multirow{2}{*}{ Del ámbito nacional } & a. $\begin{array}{l}\text { Menciones constitucionales de regí- } \\
\text { menes especiales de frontera. }\end{array}$ & $\begin{array}{l}\text { Alta potencialidad: contiene los } \\
\text { tres elementos. }\end{array}$ \\
\cline { 3 - 3 } & b. $\begin{array}{l}\text { Menciones de acompañamiento a } \\
\text { otros niveles locales por parte del Mi- } \\
\text { nisterio de Exteriores. }\end{array}$ & $\begin{array}{l}\text { Media potencialidad: contiene al } \\
\text { menos dos elementos }\end{array}$ \\
\cline { 3 - 3 } & c. $\begin{array}{l}\text { Ministerio de Exteriores es partícipe } \\
\text { de las políticas fronterizas. }\end{array}$ & $\begin{array}{l}\text { Baja potencialidad: contiene uno } \\
\text { o ningún elemento. }\end{array}$ \\
\hline
\end{tabular}

Fuente: Elaboración propia.

Tabla 2: Variables e indicadores para el ámbito fronterizo

\begin{tabular}{|l|l|l|l|}
\hline Tipo de normatividad & Elementos para medición de la potencialidad & Ponderación de la potencialidad \\
\hline & a. $\quad$ Tiene una ley de fronteras. & $\begin{array}{l}\text { Alta potencialidad: contiene los } \\
\text { tres elementos. }\end{array}$ \\
\cline { 3 - 4 } Del ámbito fronterizo. & b. $\quad \begin{array}{l}\text { Establece una normatividad especial a } \\
\text { los municipios fronterizos. }\end{array}$ & $\begin{array}{l}\text { Media potencialidad: contiene al } \\
\text { menos dos elementos }\end{array}$ \\
\cline { 3 - 4 } & c. $\begin{array}{l}\text { La concepción de frontera va más allá } \\
\text { de una mirada de defensa-soberanista. }\end{array}$ & $\begin{array}{l}\text { Baja potencialidad: contiene uno } \\
\text { o ningún elemento. }\end{array}$ \\
\hline
\end{tabular}

Fuente: Elaboración propia.

Tabla 3: Variables e indicadores para el ámbito local

\begin{tabular}{|c|c|c|}
\hline Tipo de normatividad & Elementos para medición de la potencialidad & Ponderación de la potencialidad \\
\hline & a. $\begin{array}{l}\text { Hay herramientas jurídicas que proyectan } \\
\text { los municipios no fronterizos internacio- } \\
\text { nalmente. }\end{array}$ & $\begin{array}{l}\text { Alta potencialidad: contiene } \\
\text { los tres elementos. }\end{array}$ \\
\cline { 3 - 4 } Del ámbito local. & b. $\begin{array}{l}\text { Hay normativas que le entregan autono- } \\
\text { mía a los entes territoriales estudiados. }\end{array}$ & $\begin{array}{l}\text { Media potencialidad: contie- } \\
\text { ne al menos dos elementos }\end{array}$ \\
\cline { 3 - 4 } & c. $\begin{array}{l}\text { Tienen capacidad de formular proyectos } \\
\text { de ley al parlamento nacional. }\end{array}$ & $\begin{array}{l}\text { Baja potencialidad: contiene } \\
\text { uno o ningún elemento. }\end{array}$ \\
\hline
\end{tabular}

Fuente: Elaboración propia. 


\section{Variables e indicadores por ámbitos}

\section{Del ámbito nacional}

En el análisis de las normativas que atañen al ámbito nacional (ver Tabla 4), se revisó tanto la constitución como las leyes que rigen la política exterior de los países. Para el caso colombiano, existen dentro de la Constitución Política de 1991 varios artículos que entregan un régimen especial a los territorios de frontera. Así, se enuncia dentro de la Carta Magna colombiana la posibilidad del logro de acuerdos de cooperación e integración con entidades limítrofes de otros países para el fomento del desarrollo, la búsqueda por parte de los departamentos de la financiación del desarrollo de sus zonas de frontera, la posibilidad de normas especiales para los territorios fronterizos y un apartado de la posibilidad de delegación de competencias que son exclusivamente nacionales a los departamentos en circunstancias especiales de tipo económico o cultural. Estos elementos están sustentados en los artículos 227, 289, 300 (numeral 2), 302 y 337.

Tabla 4: Potencialidades para el ámbito nacional

\begin{tabular}{|c|c|c|c|c|}
\hline Indicador/País & Colombia & Nicaragua & Panamá & $\begin{array}{l}\text { Costa } \\
\text { Rica }\end{array}$ \\
\hline $\begin{array}{l}\text { Menciones constituciona- } \\
\text { les de regímenes especiales } \\
\text { de frontera. }\end{array}$ & $\begin{array}{l}\text { Constitución: Artículos 227, } \\
289,300 \text { (numeral 2), } 302 \text { y } \\
337 .\end{array}$ & No aplica & No aplica & No aplica \\
\hline $\begin{array}{l}\text { Menciones de acompaña- } \\
\text { miento a otros niveles loca- } \\
\text { les por parte del Ministerio } \\
\text { de Exteriores. }\end{array}$ & $\begin{array}{l}\text { Decreto } 3355 \text { de 2009: Artí- } \\
\text { culo } 3 \text { en sus numerales } 8 \text {, } \\
9,10 \text { y } 15 .\end{array}$ & $\begin{array}{l}\text { Ley No. } 358 \text { de } 2000: \\
\text { artículo } 4 \text { en sus nume- } \\
\text { rales } 8,10 \text { y } 11 \text {. }\end{array}$ & No aplica & No aplica \\
\hline $\begin{array}{l}\text { Ministerio de Exteriores es } \\
\text { partícipe de las políticas e } \\
\text { intercambios fronterizos. }\end{array}$ & $\begin{array}{l}\text { Decreto } 3355 \text { de 2009: Ar- } \\
\text { tículo 3, numerales 9 y } 10 . \\
\text { Ley 191 de 1995: Artículo } 7, \\
\text { parágrafo 3. Decreto } 1030 \text { de } \\
\text { 2014: Artículo } 2 \text { y sus pará- } \\
\text { grafos } 1 \text { y } 2 \text {. }\end{array}$ & $\begin{array}{l}\text { Ley No. } 358 \text { de } 2000: \\
\text { Artículo } 4 \text {, numeral } 10 \text { y } \\
\text { 11. Ley } 749 \text { de } 2010: \text { Ar- } \\
\text { tículo 29. Decreto } 6 \text { de } \\
\text { 2011: Artículo } 21 \text {. }\end{array}$ & $\begin{array}{l}\text { Ley } 28 \text { de } \\
\text { 1999: Artículo } \\
\text { 3, numeral } 5 .\end{array}$ & No aplica \\
\hline
\end{tabular}

Fuente: Elaboración propia.

Por el lado de la política exterior, desde el ámbito normativo, vale la pena ver cuál es el papel de los ministerios de exteriores respecto a la actuación internacional de los niveles inferiores de gobierno y su participación respecto a los espacios fronterizos. En Colombia, es el Decreto 3355 de 2009 el que rige al Ministerio de Relaciones Exteriores. En este, vale la pena destacar que el Ministerio es quien articula las acciones internacionales en distintos ámbitos (económicos, culturales, comerciales, políticos, entre otros) de todos los niveles del Estado y de particulares, sin perder de vista la conveniencia nacional. Esto es importante porque muestra que el Ministerio se encuentra incluido dentro del proceso de relacionamiento hacia afuera de diversas entidades nacionales y territoriales, lo cual se acompasa con la idea del concepto previo que puede emitir respecto a los acuerdos y tratados que se vayan a firmar y su participación en los procesos de negociación de otras entidades nacionales o territoriales. Estos elementos están sustentados en el artículo 3 en sus numerales 8, 9, 10 y 15 de dicho Decreto.

Para el caso de Nicaragua, la Ley No. 358 del 2000 es la que regula la política exterior. En esta, es relevante destacar que dicho despacho tiene el mandato de participar de 
forma activa de todo esfuerzo por los procesos de integración regional, la promoción de las relaciones culturales y el estímulo para el logro de hermanamientos municipales. Es importante mencionar que más que un actor pasivo, en la legislación el Ministerio de Relaciones Exteriores nicaragüense aparece como un promotor de actividades de integración y acercamiento, además se destaca que invite a las aproximaciones culturales, ya que existe una filiación de este tipo en los países que se están investigando. Esto está sustentado en el artículo 4, numerales 8, 10 y 11 de dicha Ley.

Panamá, por su parte, establece su política exterior a través de la Ley 28 de 1999. Es importante dar cuenta aquí del artículo 3, numeral 5, en donde se establece que el Ministerio de Exteriores debe coordinar con las entidades públicas competentes lo concerniente a las fronteras y los límites del país, así como las cuestiones que refieren a las zonas fronterizas, aunque en los decretos reglamentarios no aparezca la forma en que se hará dicha coordinación. Además, en el numeral 4 de dicho artículo, es papel del Ministerio la coordinación y participación en la celebración de acuerdos y tratados de otras instituciones gubernamentales, en donde queda la pregunta sobre si se refiere a las entidades del nivel nacional o puede recaer en otras instituciones del nivel local.

En el caso de Costa Rica, no existe ningún tipo de participación del Ministerio de Exteriores en procesos de otros entes locales a nivel internacional, porque no hay tampoco ningún mecanismo claro para dichos entes de proyectarse internacionalmente como se verá más adelante. La única participación dentro del tema fronterizo, está estipulado en el Decreto 19561 de 1990 y posteriores, ya que en el artículo 8, literal G, se determina que este se ocupará de los acuerdos y tratados que delimiten las fronteras del país. Ni la Ley Orgánica 3008 de 1962, ni los decretos 19561 de 1990, 36271 de 2010 y 38435 de 2014 dan mayores pistas sobre los elementos que interesan con respecto a la conformación de una Región de Integración Transfronteriza.

\section{Del ámbito fronterizo}

Se ha mencionado ya que en esta variable se tendrán en cuenta aspectos como la existencia de una ley o normativa exclusiva para las fronteras, la configuración de normativas especiales para los municipios o departamentos de frontera y una visión más integracionista que dé defensa de la soberanía dentro de sus concepciones fronterizas (ver Tabla 5).

Tabla 5: Potencialidades para el ámbito fronterizo

\begin{tabular}{|l|l|l|l|l|}
\hline Indicador/País & Colombia & Nicaragua & Panamá & Costa Rica \\
\hline $\begin{array}{l}\text { Tiene una ley de fron- } \\
\text { teras }\end{array}$ & Ley 191 de 1995 & Ley 749 de 2010 & $\begin{array}{l}\text { Decreto Ley 8 de } \\
2008\end{array}$ & No Aplica \\
\hline $\begin{array}{l}\text { Establece una norma- } \\
\text { tividad especial a los } \\
\text { municipios fronteri- } \\
\text { zos. }\end{array}$ & $\begin{array}{l}\text { Constitución: Artículos 227, } \\
\text { 289, 300 (numeral 2), 302 y } \\
\text { 337. Ley 1551 de 2012: Artí- } \\
\text { culo 193. Ley 1454 de 2011: } \\
\text { Artículo 3, numeral 4. }\end{array}$ & $\begin{array}{l}\text { Ley 749 de 2010: Artí- } \\
\text { culos 6 (numeral 3), } \\
\text { 29, 30. Decreto 6 de } \\
\text { 2011, artículo 21. }\end{array}$ & No aplica & No aplica \\
\hline $\begin{array}{l}\text { La concepción de } \\
\text { frontera va más allá de } \\
\text { una mirada de defen- } \\
\text { sa-soberanista. }\end{array}$ & Mirada integracionista. & $\begin{array}{l}\text { Mirada integracio- } \\
\text { nista. }\end{array}$ & $\begin{array}{l}\text { Mirada de } \\
\text { defensa-soberanista. }\end{array}$ & $\begin{array}{l}\text { Mirada de } \\
\text { defensa-soberanista. }\end{array}$ \\
\hline
\end{tabular}

Fuente: Elaboración propia. 
El caso colombiano nos muestra las tres características de manera amplia en la Ley 191 de 1995 o Ley de Fronteras. En esta se establecen los elementos a través de los cuales se puede lograr una integración transfronteriza en aspectos específicos como la prestación de servicios, desarrollo de actividades económicas y sociales. Más allá de la clasificación que realiza dicha Ley (entre Zonas de Frontera, Unidades Especiales de Desarrollo Fronterizo, Zonas de Integración Fronteriza) que terminan siendo más complementarias que excluyentes, se establece la posibilidad de lograr convenios de cooperación con los entes locales de los países vecinos, con el acompañamiento del Ministerio de Relaciones Exteriores (Minexteriores) y el respaldo del gobierno nacional. ${ }^{11}$ Esto se respalda en el artículo 2, numeral 5; artículo 4, literales A, B y C; artículos 6, 7 (con su parágrafo 3) y 32. Pero además se ve complementado por el Decreto 1030 de 2014 en sus artículos 1, 2 (y sus parágrafos 1 y 2) y 5 (numeral 2), en donde el Minexteriores lidera las acciones que se puedan realizar en dichas zonas fronterizas, lo cual muestra que el asunto fronterizo debe tener un enfoque hacia afuera, y se establece la integración fronteriza como una prioridad social, política, técnica y financiera. Aun así, el decreto deja sin capacidad a los entes locales ya que no terminan siendo desequilibrantes al momento de la configuración de políticas y acciones de frontera, que se ven mucho más robustas en la Ley 191 de 1995.

Para el caso de Nicaragua, se encuentra la Ley 749 de 2010 o la Ley de Régimen Jurídico de Fronteras. En esta se enuncia el espacio fronterizo y se menciona el régimen especial que este tiene dentro del ordenamiento jurídico en el artículo 6, numeral 3. Es importante destacar que en el artículo 29 se mandata la posibilidad de acuerdos de hermanamiento por parte de los municipios fronterizos con entes homólogos en los Estados vecinos, de la mano con el Minexteriores de dicho país. Es fundamental también la potestad que tienen en el artículo 30 los pueblos indígenas y afrodescendientes a partir de los instrumentos jurídicos internacionales de lograr acuerdos de cooperación, aunque sin dejar de lado el interés nacional, según reza dicho artículo. La Ley de Régimen Jurídico de Fronteras muestra, entonces, una vocación de exteriorización de los municipios que se encuentren en los espacios fronterizos, además destacando los vínculos culturales históricos de las minorías étnicas. La reglamentación, establecida en el Decreto 6 de 2011, le da el papel al Ministerio de Exteriores de acompañar el proceso y mandata al ejecutivo de buscar convenios con los países vecinos para el logro de facilidades de movilización de personas en zonas fronterizas con los pueblos originarios, aspecto fundamental para explotar los nexos existentes en el Gran Caribe entre comunidades afrocaribeñas. Así pues, Nicaragua también cumple con los tres criterios aquí establecidos para el ámbito fronterizo, lo que lo muestra como potencial para el logro de una integración transfronteriza a través de las herramientas jurídicas en este nivel.

El caso de Panamá es bastante distinto, ya que no pasa de tener una concepción meramente soberanista de la frontera ni le brinda herramientas a los entes que se encuentran ubicados en los espacios fronterizos. El Decreto Ley 8 de 2008 es la única normatividad especial que atañe a las fronteras, pero esta refiere a un Servicio Nacional de Fronteras, liderado por la policía panameña y el Ministerio de Gobierno y Justicia, el cual cumple con la protección de los territorios, del orden público y busca evitar hechos

\footnotetext{
${ }^{11}$ A pesar de esto, no hay que perder de vista que a dicha Ley se le han hecho críticas alrededor de su concreción, por ejemplo Lizarazo y de Lombardae (1998, p. 51) afirman que:

Existe un gran número de disposiciones que reglamentan la materia, pero en la práctica no ha tenido resultado concreto en materias que fueron señaladas como objetivos de la ley: Impulsar los procesos de integración a partir de las zonas de frontera y acelerar el desarrollo político y social de las subregiones.
} 
delictivos o acciones que atenten contra la soberanía de dicho país. La única herramienta que tiene de cooperación más allá de la frontera, se la abroga el gobierno central en el artículo 22, numeral 9, ya que al ser liderado por el Ministerio de Gobierno y la Policía de Panamá, no le entrega atribuciones a los espacios fronterizos, lo cual es buena muestra del correlato que tiene con un proceso de descentralización que no se ha desarrollado a plenitud y tiene sendos vacíos (Chacón, 2014).

El caso de Costa Rica también muestra una dinámica similar, ya que aunque no tiene ningún tipo de normatividad de tipo fronterizo, sí tiene la Ley 7410 de 1994 o Ley General de Policía, la cual tiene el mandato de vigilar las fronteras terrestres y marítimas y de conservar la integridad del territorio, con lo cual deja entrever la concepción fronteriza de contención que tiene, más que una visión integracionista de la misma.

\section{Del ámbito local}

Por último, en el nivel local se intenta dar cuenta de los elementos normativos que tienen dichos entes territoriales (municipios, departamentos, regiones), tanto en su capacidad de incidencia en el ámbito nacional a través de leyes que puedan ser propuestas desde dichos entes, como en su pertenencia o no a regímenes especiales dentro del ordenamiento jurídico, y si en las leyes que los rigen existen herramientas que los proyecten internacionalmente (Tabla 6).

Tabla 6: Potencialidades para el ámbito local

\begin{tabular}{|l|l|l|l|l|}
\hline \multicolumn{1}{|c|}{ Indicador/País } & \multicolumn{1}{|c|}{ Colombia } & \multicolumn{1}{|c|}{ Nicaragua } & \multicolumn{1}{c|}{ Panamá } & \multicolumn{1}{c|}{ Costa Rica } \\
\hline $\begin{array}{l}\text { Hay herramientas jurí- } \\
\text { dicas que proyectan los } \\
\text { municipios (no fron- } \\
\text { terizos) internacional- } \\
\text { mente. }\end{array}$ & No aplica & $\begin{array}{l}\text { Ley No. 40 de 1988 (y mo- } \\
\text { dificaciones en Leyes 261 } \\
\text { de 1997 y 792 de 2012): Ar- } \\
\text { tículo 28, numeral 11. Artí- } \\
\text { culo 24, numeral 27. }\end{array}$ & No aplica & $\begin{array}{l}\text { Ley } \\
\text { 1998: Artículo 4, } \\
\text { literal F. }\end{array}$ \\
\hline $\begin{array}{l}\text { Hay normativas que le } \\
\text { entregan autonomía a } \\
\text { los entes territoriales } \\
\text { estudiados. }\end{array}$ & $\begin{array}{l}\text { Ley 47 de 1993: Artícu- } \\
\text { lo 4, literal G. Artículo } \\
\text { 4, literal J. Artículo 10, } \\
\text { literal F. Artículo 13, li- } \\
\text { teral F. }\end{array}$ & $\begin{array}{l}\text { Ley 28 de 1987: Artículo 8, } \\
\text { numeral 7. Decreto 3584 } \\
\text { de 2003: Artículo 22, literal } \\
\text { C. Artículo 5, literales Gy F. }\end{array}$ & $\begin{array}{l}\text { Decreto Ley 18 } \\
\text { de 1948. }\end{array}$ & No aplica \\
\hline $\begin{array}{l}\text { Tienen capacidad de } \\
\text { formular proyectos de } \\
\text { ley al parlamento na- } \\
\text { cional. }\end{array}$ & $\begin{array}{l}\text { Ley 134 de 1994: Artícu- } \\
\text { lo 28. }\end{array}$ & $\begin{array}{l}\text { Ley No. 40: Artículo 28, nu- } \\
\text { meral 2. }\end{array}$ & No aplica & $\begin{array}{l}\text { Ley } \\
1998: \\
13, \text { literal J. }\end{array}$ \\
\hline
\end{tabular}

Fuente: Elaboración propia.

En el caso colombiano, hay que empezar primero destacando que no existen herramientas jurídicas claras dentro de las leyes que atañen al municipio (Ley 136 de 1994, Ley 1551 de 2012, Ley 1454 de 2011) que permitan que estos se perfilen internacionalmente, exceptuando a los de frontera, en donde se refuerza la vocación integracionista de la Ley 191 de 1995. Aun así, la herramienta de formulación de proyectos de ley se presenta dentro del artículo 28 de la Ley 134 de 1994 o de Participación Ciudadana con ciertas condiciones y limitaciones que, por momentos, le quita la fuerza al alcance de dicha 
posibilidad. ${ }^{12}$ Además, existe una normatividad que brinda cierto manejo autónomo al Departamento Archipiélago de San Andrés, Providencia y Santa Catalina, ${ }^{13}$ en la Ley 47 de 1993 en donde se establecen normas especiales para este. Aquí, se destaca la posibilidad de adelantar acuerdos de cooperación e integración con las entidades territoriales de otros países, tal como se consagra para las fronteras terrestres, como ya hemos visto. Además, tiene el mandato de protección a la cultura raizal a través de acciones que logren este objetivo (protección de la lengua, desarrollo de la misma, defensa del patrimonio) lo cual es fundamental ya que el origen socio-cultural es el sustento de los municipios propuestos para dicho trabajo. Estos dos elementos están sustentados en el artículo 4 (literales G y J) y en el artículo 10 y 13 (el literal F de ambos).

El caso de Nicaragua es especial, ya que para este apartado del ámbito regional, cumple con los tres elementos propuestos aquí. En primera instancia, su legislación municipal establecida en la Ley No. 40 de 1988 y sus respectivas modificaciones (Leyes 261 de 1997 y 792 de 2012) le da la potestad al Concejo Municipal de discutir y aprobar las relaciones internacionales de dicho ente, entre ellas el hermanamiento para el logro de acuerdos de cooperación, ayuda técnica y económica en el artículo 28 (numeral 11). El Alcalde también tiene, por su parte, la potestad de proponer dichas relaciones de hermanamiento, sustentada en el artículo 34 (numeral 27). Además, en los concejos municipales pueden generarse iniciativas de ley que tengan incidencia en el ámbito nacional, en cuestiones que se encuentren dentro de su competencia, lo cual les brinda herramientas propositivas frente al gobierno central, aspecto que se encuentra sustentado en el artículo 28 (numeral 2) de dicha ley y en el artículo 140 (numeral 3) de la Constitución.

Por último, para el caso nicaragüense hay que destacar la normatividad que tienen las Regiones Autónomas del Atlántico tanto Norte como Sur. La Ley 28 de 1987 o Estatuto Autonómico de las dos Regiones de la Costa Atlántica de Nicaragua y su Decreto Reglamentario 3584 de 2003, brindan varias herramientas interesantes para el propósito de esta investigación. Por un lado, tienen iniciativa de ley respaldada en el artículo 140 de la Constitución y en el artículo 5 (literal F) de este reglamento. Además deben ser tenidos en cuenta por parte del Ministerio de Exteriores en representaciones diplomáticas en países del Caribe como reza el artículo 22 (literal C) del Decreto Reglamentario. Por último, tienen un mandato hacia la búsqueda de un intercambio tradicional con las naciones y

${ }^{12}$ En dicho artículo, se establecen las condiciones que aquí se explican de forma más explícita:

Para promover la iniciativa debe reunirse el apoyo del $0,5 \%$ de los ciudadanos inscritos en el respectivo censo electoral, constituir un comité de promotores y elegir un vocero. Cumplido lo anterior, se inscribe la iniciativa (presentada en forma de articulado) ante la Registraduría Nacional del Estado Civil quien revisa la solicitud y entrega un formulario para que allí se reúna, en un término de 6 meses, el respaldo del $5 \%$ de los ciudadanos inscritos en el respectivo censo electoral. Si esto se logra, el proyecto se presenta ante la corporación respectiva quien lo estudia siguiendo las reglas del artículo 163 Constitucional. El vocero debe ser convocado y escuchado en las sesiones en que se tramite el proyecto. Las temáticas susceptibles de ser reguladas a partir de este mecanismo se encuentran limitadas por la Constitución y la Ley. No se puede presentar en temas como: planes de desarrollo; relaciones internacionales; cuestiones fiscales y tributarias; concesión de amnistías o indultos; preservación y restablecimiento del orden público; régimen salarial y prestacional de los empleados públicos; etc., limitaciones temáticas que se encuentran expresamente señaladas en los artículos 154 Constitucional y 29 de la Ley 134 de 1994 (Echeverri, 2010, p. 69).

${ }^{13}$ Aunque se puede afirmar que San Andrés, Providencia y Santa Catalina hacen parte del entramado fronterizo nacional, la legislación no respalda totalmente dicho aspecto, ya que la Ley de Fronteras excluye a las Islas de dicho articulado. Aun así, tanto la Ley 915 de 2004, los documentos de Cancillería y su programa Plan Fronteras para la Prosperidad y el más reciente documento del Consejo Nacional de Política Económica y Social (CONPES) que refiere a las fronteras (CONPES 3805 de 2014) incluyen al Departamento Archipiélago dentro de las fronteras susceptibles de tener políticas especiales en la materia. 
pueblos del Caribe que les da cierto margen de acción de cara a la búsqueda de acuerdos transfronterizos, elemento respaldado por el artículo 5 (literal G) del Decreto.

En el caso de Panamá, apenas se puede vislumbrar la particularidad de Colón, establecida como zona libre por el Decreto Ley 18 de 1948 y que es complementada por la Ley 25 de 1992 y la Ley 54 de 1998. En esta legislación especial se establecen exenciones fiscales, arancelarias y tributarias para empresas y para productos, por su cercanía al Canal de Panamá, lo cual conlleva un amplio flujo de mercancías por dicho territorio. No implica esto ningún tipo de proyección internacional, sino simplemente una normatividad de tipo comercial para sacar provecho de la ubicación estratégica del municipio. Por demás, no hay herramientas jurídicas de proyección internacional al municipio, ni capacidades de formulación de proyectos de ley al parlamento nacional.

Costa Rica también formula exiguos elementos de cara al interés de esta investigación desde la perspectiva local. En la Ley 7794 de 1998 o Código Municipal, se puede resaltar el artículo 4 (literal F) en el cual se establece la posibilidad del logro de pactos o convenios con entidades nacionales o extranjeras que le permitan al municipio lograr el cumplimiento de sus funciones, aunque no aclare ningún mecanismo. Además, en el artículo 13 (literal J) se establece que desde el municipio, se pueden proponer proyectos de ley necesarios para el desarrollo del municipio a la Asamblea Legislativa, lo cual, le da cierto nivel de incidencia en lo nacional a los entes locales.

\section{Ejercicio comparado}

Es revelador encontrar que Colombia y Nicaragua son los países que mayores elementos brindan a sus entes territoriales para el logro de acuerdos transfronterizos. Según las variables seleccionadas, estos dos países ofrecen posibilidades normativas que pueden ser explotadas por parte de los actores locales para el desarrollo de estrategias de acercamientos más allá de las fronteras nacionales. Panamá y Costa Rica, por su parte muestran una precaria normatividad para el logro de este tipo de acuerdos, aunque para el caso de Costa Rica, la facultad de tener iniciativa de ley podría ser un desanudador de la circunstancia adversa que normativamente tiene para que sus entes territoriales de frontera logren acuerdos transfronterizos (ver Tabla 6).

Vale la pena destacar que entre más recientes son las constituciones, mayores desarrollos tienen en términos de fronteras, de autonomías municipales y de perspectivas transfronterizas. Por ejemplo las que mayores desarrollos tienen, corresponden a 1991 y 1987 (Colombia y Nicaragua), mientras que las más rezagadas responden a 1949 y 1972 (Costa Rica y Panamá). Así, los desarrollos jurídicos que de estas constituciones se emanan, tendrán un mayor o menor desarrollo, cuestión que se demuestra en la medición de potencialidades, como se observa en la Figura 2.

Otro punto importante es que existen normativas especiales para dos de los espacios fronterizos estudiados; Colombia y Nicaragua le brindan tanto a San Andrés como a las Regiones Autónomas del Atlántico (en donde se ubican Bilwi, Bluefields y Corn Island) unas potestades especiales por sus particularidades históricas, cuestión que no ocurre con los otros países y sus etnias afropanameñas y afrolimonenses. Cabe considerar no obstante, que pese al mayor potencial para la proyección fronteriza de estos territorios hacia el Caribe, lo que ha mostrado la experiencia, en buena parte de las políticas y planes de desarrollo fronterizo que despliegan los Estados nación en estas zonas, ha sido la tendencia a privilegiar una mirada del desarrollo de la frontera "hacia adentro", siendo 
todavía insuficiente el uso de las herramientas normativas para una integración que propenda por un desarrollo "hacia afuera" de la misma. ${ }^{14}$

Figura 2: Potencialidades comparadas por país

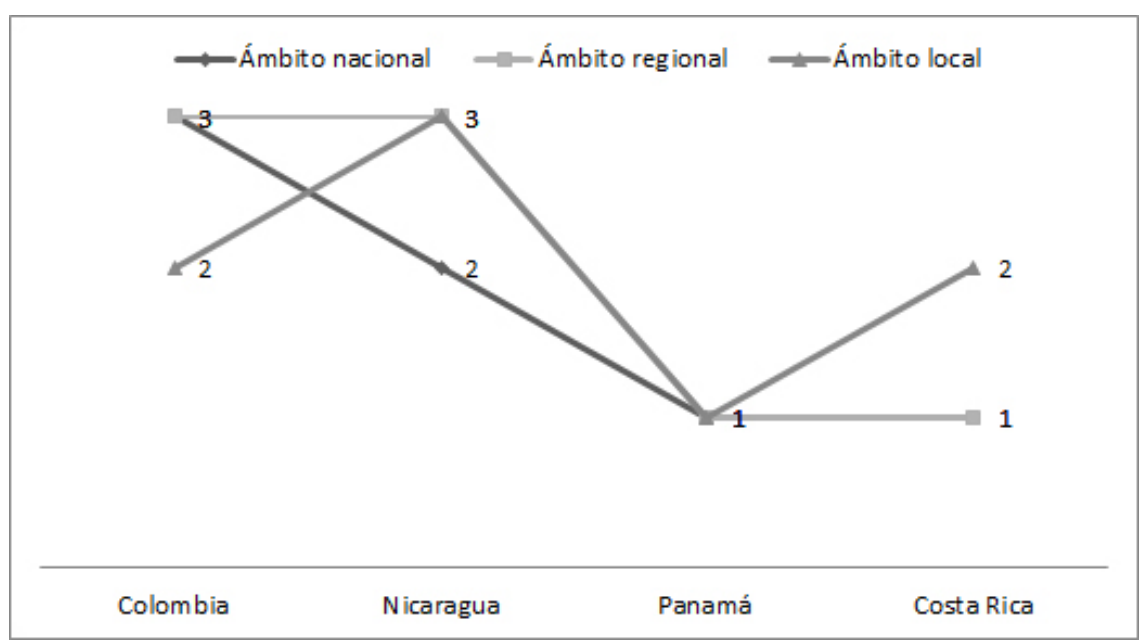

Nota: 1) Baja potencialidad, 2) Media potencialidad, 3) Alta potencialidad.

Fuente: Elaboración Propia.

La concepción soberanista de Costa Rica y Panamá de las fronteras se puede explicar, en el primer caso, por la tensión existente entre este país y Nicaragua ya que la frontera terrestre es muy permeable con lo cual se han generado conflictos bilaterales entre ambos Estados. En el segundo caso, Panamá tiene una vigilancia sobre sus mares por el tráfico de narcóticos y por la dificultad que presenta el paso del Darién en términos de seguridad. Podría decirse entonces, que estos países han preferido la soberanía antes que el desarrollo fronterizo. Los acuerdos posibles ante esta baja potencialidad y por el perfil securitario pasarían por temas de cooperación policial con los dos países.

Lo importante es que existen al menos dos países que tienen una alta potencialidad en la materia, los cuales podrían iniciar un proceso que pueda, posteriormente, vincular a otras entidades territoriales de los demás países, ante la muestra de experiencias exitosas. Los actores tanto de Colombia como de Nicaragua encuentran entonces un espacio legal útil para la búsqueda de acuerdos transfronterizos que puedan tener eco en el Gran Caribe (Véase Tabla 7).

\section{Conclusiones}

La situación de conflictos limítrofes y políticos interestatales por los que atraviesa recientemente la región del Caribe occidental ha puesto de relieve la necesidad de identificar estrategias que permitan a los actores sociales y políticos en los territorios

\footnotetext{
${ }^{14}$ Para el caso colombiano, una revisión del más reciente conPES 3805 de 2014 para las fronteras nos muestra un amplio despliegue de políticas de desarrollo fronterizo "hacia adentro", como temas de infraestructura, servicios públicos, salud, entre otros. El artículo 9 de la Ley de Fronteras nicaragüense también da buena cuenta de las funciones (hacia adentro) que tiene su Comisión para el Territorio Fronterizo. El MIDEPLAN de Costa Rica también en su plan de 2009, muestra como se ocupa exclusivamente de asuntos internos más que de proyección internacional.
} 
fronterizos de esta región, desarrollar acciones de integración como una forma de superar las visiones puramente soberanistas que los Estados nación han desplegado tradicionalmente sobre estos territorios. Una mirada a los ordenamientos jurídicos y territoriales permite identificar elementos que a largo plazo (y más allá de las divisiones ideológicas o políticas de los gobernantes de turno) pueden ser aprovechados para la construcción de una Región de Integración Transfronteriza que articule de manera flexible las necesidades de interacción y complementariedad de la sociedad caribeña que configura una unidad sociocultural diferenciada.

Hemos visto a lo largo del artículo, que tanto la configuración político territorial, como el contexto jurídico cobran relevancia, en los espacios en los cuales los actores locales se encuentran imbuidos y en donde estos encuentran los márgenes de acción que pueden posibilitar o no el logro de acuerdos transfronterizos. Debe tenerse en cuenta para un análisis más profundo, una revisión de los procesos de descentralización en los cuatro países, que en términos generales pueden ser considerados como procesos inacabados ya sea por una fallida puesta en práctica o por una muy escasa legislación descentralizadora (Chacón, 2014).

Tabla 7: Resumen de las potencialidades por país y ejercicio comparado

\begin{tabular}{|c|c|c|c|}
\hline Indicador/Variable & Alta Potencialidad & Media Potencialidad & Baja Potencialidad \\
\hline Del ámbito nacional & $\begin{array}{l}\text { Colombia: sustentado en Constitución: Artícu- } \\
\text { los } 227,289,300 \text { (numeral 2), } 302 \text { y } 337 \text {. Decre- } \\
\text { to } 3355 \text { de } 2009 \text { : Artículo } 3 \text { en sus numerales } \\
8,9,10 \text { y 15. Ley } 191 \text { de 1995: Artículo } 7 \text {, pará- } \\
\text { grafo } 3 \text {. Decreto } 1030 \text { de 2014: Artículo } 2 \text { y sus } \\
\text { parágrafos } 1 \text { y } 2 \text {. }\end{array}$ & $\begin{array}{l}\text { Nicaragua: Sustentado en Ley } \\
\text { No. } 358 \text { de 2000: artículo } 4 \text { en } \\
\text { sus numerales } 8,10 \text { y } 11 \text {. Ley } 749 \\
\text { de 2010: Artículo } 29 \text {. Decreto } 6 \\
\text { de 2011: Artículo } 21 \text {. }\end{array}$ & $\begin{array}{l}\text { Panamá: Sustentado en } \\
\text { Ley } 28 \text { de 1999: Artículo } \\
\text { 3, numeral 5. } \\
\text { Costa Rica: No tiene } \\
\text { normatividad referida a } \\
\text { las variables. }\end{array}$ \\
\hline Del ámbito fronterizo & $\begin{array}{l}\text { Colombia: Sustentado en Ley } 191 \text { de } 1995 \text {, } \\
\text { Constitución: Artículos 227, 289, } 300 \text { (numeral } \\
\text { 2), } 302 \text { y 337. Ley } 1551 \text { de 2012: Artículo } 193 . \\
\text { Ley } 1454 \text { de 2011: Artículo 3, numeral 4. Mira- } \\
\text { da integracionista. } \\
\text { Nicaragua: Sustentado en Ley } 749 \text { de 2010: Artí- } \\
\text { culos } 6 \text { (numeral 3), 29, 30. Decreto } 6 \text { de } 2011 \text {, } \\
\text { artículo 21. Mirada Integracionista. }\end{array}$ & & $\begin{array}{l}\text { Panamá: Sustentado en } \\
\text { Decreto Ley } 8 \text { de } 2008 . \\
\text { Mirada Soberanista. } \\
\text { Costa Rica: Mirada sobe- } \\
\text { ranista. }\end{array}$ \\
\hline Del ámbito local & $\begin{array}{l}\text { Nicaragua: Sustentado en Ley No. } 40 \text { de } 1988 \\
\text { (y modificaciones en Leyes } 261 \text { de } 1997 \text { y } 792 \\
\text { de 2012): Artículo 28, numeral 11. Artículo } 34 \text {, } \\
\text { numeral 27. Artículo 28, numeral } 2 \text {. }\end{array}$ & $\begin{array}{l}\text { Costa Rica: Sustentado en Ley } \\
7794 \text { de 1998: Artículo 4, literal } \\
\text { F. Artículo 13, literal J. } \\
\text { Colombia: Sustentado en Ley } 47 \\
\text { de 1993: Artículo 4, literal G. Ar- } \\
\text { tículo 4, literal J. Artículo 10, li- } \\
\text { teral F. Artículo 13, literal F. Ley } \\
\text { 134 de 1994: Artículo 28. }\end{array}$ & $\begin{array}{l}\text { Panamá: Sustentado en } \\
\text { Decreto Ley } 18 \text { de } 1948 .\end{array}$ \\
\hline
\end{tabular}

Fuente: Elaboración propia.

Igualmente, es de considerar que los territorios de frontera de los países analizados, conforman un corredor ampliamente marginalizado desde el punto de vista social y económico respecto de las dinámicas centrales del desarrollo de los respectivos Estados nación, implicando la necesidad apremiante de resolver problemas estructurales básicos, lo cual podría constituirse en el principal desafío para el establecimiento de prácticas institucionales efectivas y de largo plazo para el logro de la integración fronteriza.

No obstante lo anterior, los elementos jurídicos podrían ser las herramientas que los actores podrían movilizar para el logro de la integración transfronteriza. La existencia de iniciativas 
de ley en los cuatro países, por ejemplo, podrían impulsar leyes de frontera que vinculen a los entes locales dentro del Gran Caribe, o que en países donde existen ya leyes de frontera, se puedan dinamizar relaciones por fuera de los espacios nacionales. Además, se puede hacer uso de las autonomías especiales existentes (casos de Nicaragua y Colombia) para iniciar procesos que rompan con el enclave nacional. Ello pone de relieve la necesidad de reconocer la potestad de los municipios de pactar convenios sin necesidad de crear personas jurídicas específicas, a través del reconocimiento de su accionar internacional, que contribuya con el desarrollo de estrategias de integración "desde abajo" (CESPI, 2011, p. 73).

Como pudimos observar en el análisis comparativo de los cuatro países estudiados, se puede concluir que entre más modernas y profundas han sido las dinámicas de reformas constitucionales, descentralización y de desarrollo de las normativas fronterizas, mayores son las posibilidades que tienen los actores locales de agenciar políticas de integración transfronterizas. Colombia y Nicaragua mostraron ser aquellos países cuyos entes territoriales y desarrollos normativos en sus distintos niveles de gobierno, cuentan con mayores herramientas jurídicas y administrativas para el logro de una política de integración transfronteriza hacia el Gran Caribe. Este hallazgo es de especial importancia teniendo en cuenta que son los dos países cuya confrontación por conflictos limítrofes en el área marítima del Caribe es especialmente crítica y requiere soluciones urgentes. Panamá y Costa Rica por su parte, evidenciaron una precaria potencialidad en términos normativos y de organización territorial que dificulta sus posibilidades de integración transfronteriza. Pese a ello, la detección de herramientas jurídicas dentro de los ordenamientos nacionales resulta un ejercicio vital para identificar potencialidades y necesidades ante la posible movilización de recursos por parte de los actores locales en el logro de la integración.

Dos elementos quedan abiertos entonces para la discusión en el caso específico del Caribe: en primer lugar, que la integración fronteriza en el Caribe implica necesariamente una mirada a modelos normativos y de administración de zonas marítimas por ser esencialmente el mar el espacio en que se desarrollan los intercambios económicos y societales. Ello no desecha la importancia de revisar los ordenamientos territoriales y jurídicos que aquí hemos analizado, puesto que sin los actores sociales y sus posibilidades de articulación hacia adentro y hacia afuera de los espacios nacionales, el mar sería un espacio baldío que por sí solo no podría ser objeto de políticas o acuerdos funcionales a la integración. Tendrán que revisarse entonces, modelos novedosos y flexibles de administración conjunta del mar que contribuyan a la formación de áreas costeras y marinas integradas.

Finalmente, cabe reconocer aquí el aspecto más importante: que las posibilidades de articulación de la región transfronteriza en el Caribe no dependen necesariamente de modelos normativos o territoriales de integración regional, ni siquiera de instituciones de carácter supra o transnacionales que regulen burocráticamente el proceso integrador; la integración fronteriza puede responder a dinámicas autónomas de carácter societal que prescindan de los aparatajes institucionales en los Estados y sus localidades y que incluso los controviertan o desconozcan, como de hecho ya ha venido sucediendo recientemente en procesos autónomos de relacionamiento y hermanamiento entre actores sociales fronterizos en Colombia y Nicaragua. ${ }^{15}$ Consideramos no obstante, que la existencia de

\footnotetext{
${ }^{15}$ Luego del fallo de la Corte Internacional de Justicia un movimiento autonomista de raizales de San Andrés (grupo AMEN) suscribió el 12 de diciembre de 2014 y sin apoyo o respaldo del Estado colombiano, un acuerdo de hermanamiento con el pueblo ancestral de la Región Autónoma del Atlántico Sur en Nicaragua (Raizales y Nicaragüenses, 2014).
} 
herramientas jurídicas y de procesos autonómicos favorecidos por los Estados nación dentro de sus respectivos marcos normativos y de organización territorial, constituyen un entorno propicio para que las sociedades fronterizas a través de escenarios autónomos y descentralizados, puedan tramitar sus demandas, empoderarse de sus recursos y hacer valer sus derechos básicos a partir de sus vínculos culturales, económicos y sociales.

\section{Referencias}

Buursink, J. (2001). The Binational reality of border-crossing cities. GeoJournal, 54(1), $7-19$.

Centro Studi di Politica Internazionale (CESPI). (2011). Conceptualización de la cooperación fronteriza en el sistema de la integración centroamericana ideas y prácticas para la construcción de las microrregiones de integración. Recuperado de http://www.cespi. it/PDF/CONCEPTUALIZACI\%C3\%93N\% 20\% 20COOPERACI\%C3\%93N\% 20 FRONTERIZA.pdf

Chacón, C. (2014). Notas sobre la descentralización en cuatro países del gran Caribe de cara a pensar una integración transfronteriza. Recuperado de https://www.academia.edu/12070725/ Notas_sobre_la_descentralizaci\%C3\%B3n_en_cuatro_pa\%C3\%ADses_del_gran_Caribe_ de_cara_a_pensar_una_integraci\%C3\%B3n_transfronteriza

Church, A. y Reid, P. (1999). Cross-borders co-operation, institutionalization, and political space across the English Channel. Regional Studies, 33(7), 643-655.

Echeverri, C. F. (2010). La participación ciudadana en Colombia. Reflexiones desde la perspectiva constitucional y la normatividad estatutaria. Revista Estudios de Derecho, 67(149), 63-86.

Grimson, A. (2003). Disputas sobre la frontera. En S. Michaelsen y D. Johnson (Comps.), Teoría de la frontera. Los límites de la política cultural (pp. 13-24). Madrid, España: Gedisa.

Jessop, B. (2003). The political economy of scale and the construction of cross-border micro-regions. En F. Söderbaum y T. Shaw (Eds.), Theories of New Regionalism. A Palgrave Macmillan Reader (pp. 179-196). Basingstoke: Palgrave.

Lizarazo, L. y Lombardae, P. de (1998). Zonas de frontera en Colombia: Nuevo instrumento para el desarrollo regional a través de la cooperación internacional. Papel Político, (80), 35-53.

Lugo, A. (2003). Reflexiones sobre la teoría de la frontera, la cultura y la nación. En S. Michaelsen y D. Johnson (Comps.), Teoría de la frontera. Los límites de la política cultural (pp. 63-86). Madrid, España: Gedisa.

Raizales y nicaragüenses del Caribe suscriben acuerdo. (14 de diciembre de 2014). El Isleño. Recuperado de http://www.elisleño.com/index.php?option=com_conten t\&view=article\&id=8760:raizales-y-nicaragueenses-del-caribe-suscriben-acuerdo\&ca tid $=67$ :internacional\&Itemid $=112$

Sahlins, P. (2000). Repensando Boundaries. En A. Grimson (Comp.), Fronteras, naciones e identidades. La periferia como centro (pp. 41-74). Buenos Aires, Argentina: Ediciones Ciccus, La Crujía.

Sandner, G. (2003). Centroamérica y el Caribe Occidental: Coyunturas, crisis y conflictos 1503-1984. San Andrés, Colombia: Universidad Nacional de Colombia, Instituto de Estudios Caribeños.

Söderbaum, F. (2005). Exploring the links between Micro-Regionalism and Macro- 
Regionalism. En M. Farell, B. Hette y L. van Langerhove (Eds.), Global politics of regionalism. Theory and Practice (pp. 87-103). Londres: Pluto Press.

Sohn, C. (2014). Modelling cross-border integration. The role of borders as a resource. Geopolitics, 3(19), 587-608.

Stelmakh, A. (s.f.). Efficiency of ENPI cross-border cooperation program in the Black Sea Region as a tool to enhance cooperation at a regional level. Recuperado de https://www.academia. edu/1951896/EFFICIENCY_OF_ENPI_CROSS-BORDER_COOPERATION_PROGRAM_ IN_THE_BLACK_SEA_REGION_AS_A_TOOL_TO_ENHANCE_COOPERATION_AT_A_ REGIONAL_LEVEL

\section{Material legislativo}

Constitución Política de Colombia, 1991, Colombia.

Constitución Política de Nicaragua, 1987, Nicaragua.

Decreto 19561 Reglamento Tareas y Funciones Ministerio Relaciones Exteriores, Diario Oficial No. 81, Art. 8, literal G (1990). Costa Rica.

Decreto 3355 Por medio del cual se modifica la estructura del Ministerio de Relaciones Exteriores y se dictan otras disposiciones, Diario Oficial No. 47.465, Art. 3, numeral 8 (2009). Colombia.

Decreto 3355 Por medio del cual se modifica la estructura del Ministerio de Relaciones Exteriores y se dictan otras disposiciones, Diario Oficial No. 47.465, Art. 3, numeral 9 (2009). Colombia.

Decreto 3355 Por medio del cual se modifica la estructura del Ministerio de Relaciones Exteriores y se dictan otras disposiciones, Diario Oficial No. 47.465, Art. 3, numeral 10 (2009). Colombia.

Decreto 3355 Por medio del cual se modifica la estructura del Ministerio de Relaciones Exteriores y se dictan otras disposiciones, Diario Oficial No. 47.465, Art. 3, numeral 15 (2009). Colombia.

Decreto 3584 Reglamento a la Ley No. 28 Estatuto de autonomía de las regiones de la costa atlántica de Nicaragua, Diario Oficial (Separata) del 2003-10-02, Art. 22, literal C (2003). Nicaragua.

Decreto 3584 Reglamento a la Ley No. 28 Estatuto de autonomía de las regiones de la costa atlántica de Nicaragua, Diario Oficial (Separata) del 2003-10-02, Art. 5, literal G y F (2003). Nicaragua.

Decreto 36271 Reforma Reglamento Tareas y Funciones Ministerio Relaciones Exteriores, Diario Oficial No. 99 (2010). Costa Rica.

Decreto 38435 Reforma Reglamento Tareas y Funciones Ministerio Relaciones Exteriores, Diario Oficial No. 99 (2014). Costa Rica.

Decreto 6 Reglamento de la Ley No. 749 Ley de Régimen Jurídico de Fronteras, Diario Oficial No. 33, Art. 21 (2011). Nicaragua.

Decreto Ley 18 Por el cual se crea la zona libre de Colón como entidad autónoma del Estado, Diario Oficial No. 10633 (1948). Panamá.

Decreto Ley 8 Que crea el Servicio Nacional de Fronteras de la República de Panamá, Diario Oficial No. 26109, Art. 22, numeral 9 (2008). Panamá.

Decreto No. 1030, Diario Oficial de la República de Colombia, Art. 1 (2014). 
Decreto No. 1030, Diario Oficial de la República de Colombia, Art. 2 \$1 y 2 (2014).

Decreto No. 1030, Diario Oficial de la República de Colombia, Art. 5, numeral 2 (2014).

Ley 136 Por la cual se dictan normas tendientes a modernizar la organización y el funcionamiento de los municipios, Diario Oficial No. 41.337 (1994). Colombia.

Ley 1454 Por la cual se dictan normas orgánicas sobre ordenamiento territorial y se modifican otras disposiciones, Diario Oficial No. 48.115, Art. 3, numeral 4 (2011). Colombia.

Ley 25 Por el cual se establece un régimen especial, integral y simplificado para la creación y funcionamiento de zonas procesadoras para la exportación, Gaceta Oficial República de Panamá (1992). Panamá.

Ley 54 Por la cual se dictan medidas para la estabilidad jurídica de las inversiones, Gaceta Oficial República de Panamá (1998). Panamá.

Ley 134 o de Participación Ciudadana, Diario Oficial de la República de Colombia, Art. 28 (1994). Colombia.

Ley 1551 Por la cual se dictan normas para modernizar la organización y el funcionamiento de los municipios, Diario Oficial No. 48.483, Art. 193 (2012). Colombia.

Ley 191 Por medio de la cual se dictan disposiciones sobre Zonas de Frontera, Diario Oficial No. 41.903, Art. 2, numeral 5 (1995). Colombia.

Ley 191 Por medio de la cual se dictan disposiciones sobre Zonas de Frontera, Diario Oficial No. 41.903, Art. 4, literales A, B y C (1995). Colombia.

Ley 191 Por medio de la cual se dictan disposiciones sobre Zonas de Frontera, Diario Oficial No. 41.903, Art. 6 (1995). Colombia.

Ley 191 Por medio de la cual se dictan disposiciones sobre Zonas de Frontera, Diario Oficial No. 41.903, Art. 7 § 3 (1995). Colombia.

Ley 191 Por medio de la cual se dictan disposiciones sobre Zonas de Frontera, Diario Oficial No. 41.903, Art. 32 (1995). Colombia.

Ley 261 Reformas e incorporaciones a la Ley No. 40, Ley de Municipios, Diario Oficial No. 62 (1997). Nicaragua.

Ley 28 Estatuto de Autonomía de las regiones de la Costa Atlántica de Nicaragua, Diario Oficial No. 238, Art. 8, numeral 7 (1987). Nicaragua.

Ley 28 Por la cual se dicta la Ley Orgánica del Ministerio de Relaciones Exteriores y se establece la carrera diplomática y consular, Art. 3, numeral 4 (1999). Diario Oficial No. 23.838. Panamá.

Ley 28 Por la cual se dicta la Ley Orgánica del Ministerio de Relaciones Exteriores y se establece la carrera diplomática y consular, Art. 3, numeral 5 (1999). Diario Oficial No. 23.838. Panamá.

Ley 3008 Ley Orgánica del Ministerio de Exteriores y Culto, Diario Oficial No. 166 (1962). Costa Rica.

Ley No. 40 Ley de Municipios, Diario Oficial No. 155, Art. 28, numeral 2 y 11 (1988). Nicaragua.

Ley No. 40 Ley de Municipios, Diario Oficial No. 155, Art. 34, numeral 27 (1988). Nicaragua.

Ley 47 Por la cual se dictan normas especiales para la organización y el funcionamiento del Departamento Archipiélago de San Andrés, Providencia y Santa Catalina, Diario Oficial No. 40.763, Art. 4, literales G y J (1993). Colombia.

Ley 47 Por la cual se dictan normas especiales para la organización y el funcionamiento del Departamento Archipiélago de San Andrés, Providencia y Santa Catalina, Diario 
Oficial No. 40.763, Art. 10, literal F (1993). Colombia.

Ley 47 Por la cual se dictan normas especiales para la organización y el funcionamiento del Departamento Archipiélago de San Andrés, Providencia y Santa Catalina, Diario Oficial No. 40.763, Art.13, literal F (1993). Colombia.

Ley 7410 Ley general de policía, Diario Oficial No. 103 (1994). Costa Rica.

Ley 749 Ley de régimen jurídico de fronteras, Diario Oficial No. 244, Art. 6, numeral 3 (2010). Nicaragua.

Ley 749 Ley de régimen jurídico de fronteras, Diario Oficial No. 244, Art. 29 (2010). Nicaragua.

Ley 749 Ley de régimen jurídico de fronteras, Diario Oficial No. 244, Art. 30 (2010). Nicaragua.

Ley 7794 Código Municipal, Diario Oficial No. 94, Art. 13, literal J (1998). Costa Rica.

Ley 7794 Código Municipal, Diario Oficial No. 94, Art. 4, literal F (1998). Costa Rica.

Ley 792 Ley de reformas a la ley No. 40, Ley de Municipios, Diario Oficial No. 109 (2012). Nicaragua.

Ley No. 358. Ley de servicio exterior, Diario Oficial No. 188, Art. 4, numeral 8 (2000). Nicaragua.

Ley No. 358. Ley de servicio exterior, Diario Oficial No. 188, Art. 4, numeral 10 (2000). Nicaragua.

Ley No. 358. Ley de servicio exterior, Diario Oficial No. 188, Art. 4, numeral 11 (2000). Nicaragua.

\section{Silvia Cristina Mantilla Valbuena}

Colombiana. Doctora en Migraciones y Conflictos en la Sociedad Global. Actualmente se encuentra adscrita a la Universidad Nacional de Colombia Sede Caribe. Líneas de investigación: estudios fronterizos en Colombia, conflicto armado y seguridad en Colombia y la región andina, migraciones transfronterizas. Entre sus publicaciones recientes se encuentran: "Articulaciones 'glocales' y transfronterizas del conflicto armado colombiano en la Amazonía colombo-ecuatoriana” (2014), en la Revista Confines de Relaciones Internacionales, y "Economía y conflicto armado en Colombia: los efectos de la globalización en la transformación de la guerra" (2012), en Latinoamérica Revista de Estudios Latinoamericanos, número 55.

\section{Christian Chacón Herrera}

Colombiano. Pregrado, politólogo de la Universidad Nacional de Colombia. Actualmente es miembro del grupo de investigación en Relaciones Internacionales y Asuntos Globales (RIAG) en la Universidad Nacional de Colombia. Líneas de investigación: fronteras, cooperación internacional para el desarrollo y política exterior. Autor de La cooperación internacional en Colombia: nuevos marcos, nuevos retos (2012). 